\title{
Measurement of Functional Ability and Health Status in the Arthritic Patient
}

Johannes W.G. Jacobs $\mathrm{MD}, \mathrm{PhD}^{\mathrm{a}}$, Agnes van der Heide, $\mathrm{MD}^{\mathrm{a}}$, Johannes J. Rasker, $\mathrm{MD}, \mathrm{PhD}^{\mathrm{b}}$ and Johannes W.J. Bijlsma, MD, $\mathrm{PhD}^{\mathrm{a}}$

${ }^{a}$ Department of Rheumatology F02.223, University Hospital Utrecht, P.O. Box 85500, 3508 GA Utrecht, and ${ }^{b}$ Department of Rheumatology, Hospital 'Medisch Spectrum Twente', Enschede (Netherlands)

\begin{abstract}
Chronic arthritis may have great impact on the patient but also on his or her family, relatives and friends. The assessment of the consequences of chronic arthritis and the effect of therapy not only in terms of physical, but also psychological and social dimensions deserves more attention. Functional ability and health status can be measured using a questionnaire or 'instrument', high-lighting important aspects not quantified with more traditional measurements. In this paper, arguments to apply such instruments more frequently are given. Health status instruments can be used not only to assess beneficial but also deleterious (side-)effects of therapeutic interventions. The properties are summarized of the most frequently used instruments assessing functional ability and health status. Many of these instruments have been evaluated sufficiently for validity and reliability; their sensitivity to detect change seems to be satisfactory. Therefore it is advisable to choose an internationally accepted, frequently used instrument, reflecting the area of interest.
\end{abstract}

Key words: Functional ability; Health status; Questionnaire; Instrument; Arthritis.

\section{Introduction and Definitions}

The effect of treatment in patients with rheumatic diseases, e.g. rheumatoid arthritis (RA), can not be assessed very easily. Since curing of the disease is, as yet, for most rheumatic diseases not possible, treatment is practically always aimed at alleviating symptoms. A gold standard to decide on the success or failure of a therapeutic intervention is not available. The course of RA is currently most often evaluated by using traditional measures of inflammation, e.g. the number of inflamed joints, morning stiffness and laboratory parameters like the erythrocyte sedimentation rate (ESR) and C-reactive protein (CRP), that give an idea mainly of the degree of inflammation present (Van der Heide et al., 1992). To assess the consequences of joint inflammation, function is assessed, e.g. by measuring grip strength, and radiographs are used to visualize the degree of joint destruction. These traditional assessments of arthritis (Table 1) are predominantly based on physical aspects of the disease and are - to a more or lesser extent - measures of the disease process, the abnormal physiologic occurrences that follow from the cause(s) of the disease (Kirwan, 1992). This holds especially true for clinically assessed joint synovitis, ESR and CRP.

The impact (rheumatic) diseases have on patients is determined however not only by physical, but also by psychological and social dimensions, according to the definition of health of the World Health Organisation (WHO). The assessment also of subjective aspects of health problems not addressed by conventional measures receives more atten- 
Table 1. Traditional assessment of arthritis.

A. Pain (dolor)

- Pain-scales: numeric rating scale, visual analogue scale

- Number of analgesic tablets used

- Joint tenderness: articular indexes e.g. Ritchie score

B. Swelling (tumor)

- Joint circumference: jeweller's rings

- Swollen joint counts

C. Redness (rubor)

(Not used in trials)

- Inspection

D. Temperature (calor)

(Seldom used in trials)

- Palpation

- Thermography

E. Stiffiness (rigor)

- Duration of morning stiffness

F. Function (functio laesa)

- Range of motion (goniometer)

- Grip strength

- Walking time

G. Other measures of inflammation

- ESR, haemoglobin, acute-phase proteins

- Bone scintigraphy (perfusion and diffusion phase)

H. Joint destruction

- Radiographical scores e.g. Larsen score (Genant, 1983).

tion lately, not only in rheumatology but also in other fields of health care. This can be done applying a questionnaire, also called an instrument'. Often, these instruments are filled out by patients themselves: self-report, selfassessment or self-completed questionnaires. Other lists may be filled out by an observer, interviewer or by the rheumatologist.

Multidimensional instruments assessing health may be labelled 'health status instruments'. These instruments predominantly address outcome of disease in contrast to the above mentioned traditional measures, outcome defined as the suffering or loss of health, experienced by an individual as a result of the process of the disease (Kirwan, 1992). Instruments, that address one specific aspect of health like psychological well-being or functional ability are called 'dimension specific instruments'; questionnaires that measure the value or preference patients attach to aspects of their health status 'utility instruments'. There are 'disease specific' and 'generic' functional ability and health status instruments: we will go into this later. The frequently used terms 'score', 'index' and 'scale' refer to the method of summarizing the responses to the individual items of the questionnaire into a global score. Although it is certainly in vogue to use for health status questionnaires the synonym 'quality of life' instruments, it can be argued that the former name is more appropriate, for the simple reason these instruments only deal with health related quality of life, and usually do not include aspects of quality of life, that have nothing to do with individual health care.

This review will focus on functional ability and health status instruments in patients with RA, but it has relevance for other rheumatic diseases too.

\section{Why Should Functional Ability and Health Status be Assessed?}

The goal of treating an individual patient with RA is to alleviate symptoms and to prevent deterioration of his or her health status in the future. In these patients, health status is influenced by pain, stiffness and other signs of inflammation and disability with handicap and psychological repercussions (Fig. 1). The evaluation of the course and outcome of RA in clinical trials and observational studies by measuring only symptoms and signs of inflammation has therefore important drawbacks. The picture is incomplete: dimensions like functional disability, psychological problems and handicap with their repercussions are not well covered. In RA, like in other chronic diseases, there is a considerable interaction between physical aspects of the 
Fig. 1. Dimensions of chronic arthritis influencing health status*.

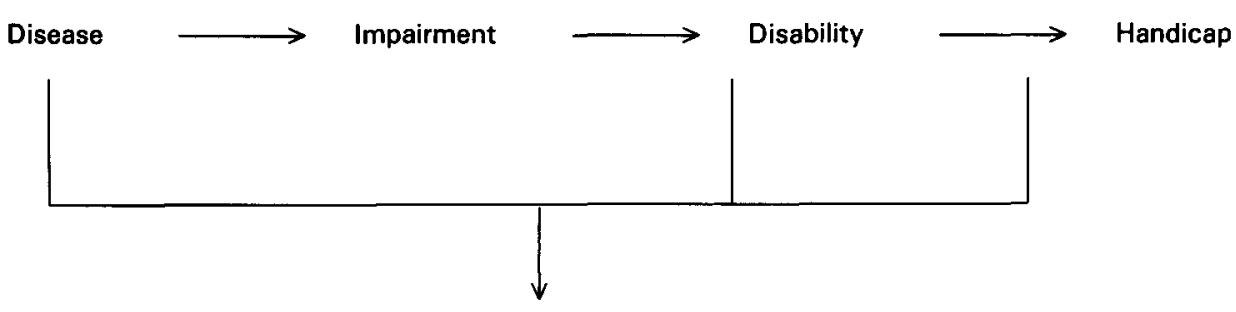

Health Status, consisting of

A. Physical aspects, e.g. malaise, disability; pain

B. Psychological aspects, e.g. anxiety, depression

C. Social aspects, e.g. social integration handicap, role performance

*Example: rheumatoid arthritis causing pain and malaise (disease), and a fixed flexion deformity of the knee (impairment), leading to reduction of ability to walk (disability), causing restrictions in social contacts and occupation (handicap).

Methods to assess these dimensions e.g.:

- Disease activity: ESR, Ritchie score (Ritchie et al., 1986)

- Impairment: Keitel Index (Keitel et al., 1991)

- Disability: Stanford Health Assessment Questionnaire (Fries et al., 1980)

- Health status: Arthritis Impact Measurement Scales (Meenan et al., 1980 and 1992)

disease and psychological and social functioning. Functional disability can, for instance, have an important influence on a patient's mood, and difficulty in walking can reduce people's social contacts (Cornelissen et al.,
1988). On the other hand, depression and loneliness may worsen the handicap and pain a patient experiences. Measuring functional ability and health status not only provides a more comprehensive picture of the course of

Table 2. Functional ability and health status instruments ${ }^{a}$.

\section{Generic Measures}

IWB

RAND

SIP

Arthritis Specific Measures $^{\mathrm{b}}$

ARA

KATZ

KI

LEE

TFCQ

AIMS1

HAQ

FSI

MHIQ

MACTAR

ACR

AIMS2
Index of Well-Being

Rand Health Insurance Study

Sickness Impact Profile
Bush

Brook

Bergner

Steinbrocker

Katz

Keitel

Lee

Helewa

Meenan

Fries

Jette

Chambers

Tugwell

Hochberg

Meenan
(1976)

Preference Disability Questionnaire

ACR functional classification

Arthritis Impact Measurement Scales 2

${ }^{a}$ Frequently used measures; the list is not intended to be complete.

${ }^{b}$ Designed primarily for use in patients with rheumatic diseases. 
RA in groups of patients, but also enables us to study the consequences of the disease more individualized. This is illustrated by the next example. A concert pianist with arthritis of one or two proximal interphalangeal joints of his hands has, according to traditional measures, relatively mild RA. This "mild" disease however, has very serious consequences for the health status of our patient, since he is not able to work any more; probably there are psychological and other social consequences too. Thus, by applying a health status instrument, these important aspects are also assessed, which is not the case if only traditional measures are used.

Also in the evaluation of efficacy of complementary and alternative treatments, that are widely used all over the world in patients with chronic rheumatic diseases, traditional measures give an incomplete picture. Health status instruments can provide a holistic evaluation of complementary treatments, so that these treatments can be properly studied in clinical trials too (Jacobs et al., 1991).

Another example. In clinical practice and most trials mostly clear cut side effects are recorded, especially if they lead to discontinuation of therapy; side effects that are not as serious very often play an unimportant role in the evaluation of the effect of drugs. This traditional strategy does not sufficiently evaluate the impact of side effects of drugs on individual health status. Drug side effects are less a problem in diseases that can be cured over a short time, and in cases where there are no alternative drugs. In chronic rheumatic diseases, where drugs are prescribed for longer times and the disease is not cured, even ill defined minor drug side effects, that can be assessed by health status instruments, are very important.

There are situations in which traditional assessment of arthritis is not only incomplete but even inappropriate. Health status instruments can assess health problems not addressed by traditional measures of arthritis nor conventional epidemiologic measures. It can provide appropriate data when political decisions have to be made regarding health care, medical costs and financial resources (Spiegelhalter et al., 1992). In this way, essential requirements, e.g. for adequate local community care, occupational therapy and so forth can be determined. For this purpose, health status and survival data are frequently combined into a single measure, e.g. the quality adjusted life years (Fitzpatrick et al., 1992). The assessment of the efficacy of patient education and other multi-disciplinary treatment programs that are intended to augment self-efficacy, that is patients' confidence that they can manage pain and other symptoms of arthritis and that they are able to perform tasks of daily living, cannot properly be done by using traditional measures of disease activity, since these treatments are not aimed at improving disease process. Health status and dimension specific instruments can measure coping with the disease and other psychological and behavioral aspects.

\section{How Can Functional Ability and Health Status be Assessed?}

Patients could be asked to grade on a scale the health status they experience. A standard question, using a visual analogue scale that range from "very well" to "very poor" could be: "Considering all the ways your arthritis affects you, mark on the scale how well you are doing". A numeric rating scale can also be used for this purpose. Such global assessments by the patient, however, do not address the different dimensions of health status in detail. Health status instruments are more appropriate. They comprise items on physical, social and emotional functions in more or less detail, depending on which instrument is used. In rheumatology, functional ability and health status instruments can be divided in generic and arthritis specific classifications, indexes or instruments (Table 2).

Arthritis specific instruments are primarily developed for use in patients with rheumatic 
diseases, but generic instruments can be applied in patients with rheumatic diseases too. Arthritis specific functional ability and health status instruments focus on arthritis specific consequences of disease e.g. in terms of disability and handicap (Fig. 1). Generic health status instruments have the advantage that they can be used in groups of patients with various disease entities, facilitating comparisons among different disease groups. Furthermore, the chance of missing effects in dimensions that are not included is less in generic than in arthritis specific instruments. An important drawback of generic instruments however, is that they lack specificity in populations with rheumatic diseases. Specificity may be low, because these instruments not only address dimensions of arthritis, but also comprise questions in areas that are usually not affected by rheumatic diseases, such as incontinence and vision. Furthermore symptoms are sometimes more heavily weighted than functional categories: a bed-ridden arthritic patient could be rated higher in physical health than a patient who can walk with a cane, depending on these patients' symptoms, specific impairments and social support. Also sensitivity may be low since areas that are indeed important determinants of functional ability and health status of rheumatic patients, such as mobility and fine hand function, are either not included or only superficially covered by some generic instruments.

\section{Which are the Properties of Frequently used In- struments?}

Requirements of functional ability and health status instruments are reliability-that is that they must produce the same results under repeated use under the same conditions- and validity (Bombardier and Tugwell, 1983). Face validity is present if the instrument seems to cover the full range of relevant topics; construct validity is concerned with the relations of the instrument with other more established measures. The latter is in- vestigated determining the extent of agreement with laboratory or clinical measures of severity of disease or determining the ability of the instrument to distinguish between groups of patients with different levels of health status. For the use in clinical trials, sensitivity to change of the instrument is a prerequisite. The properties of frequently used instruments are specified in Table 3. Most of the instruments have been sufficiently evaluated for validity, that is that they do measure what they are supposed to, and reliability or reproducibility. Sensitivity to detect change is in general less frequently investigated (American College of Rheumatology, 1988, Liang et al., 1983, Bombardier and Tugwell, 1983, Bell et al., 1990). Of the in Table 2 and 3 listed instruments, only of the ARA functional classification, reliability and validity are unknown. This global classification is probably not sensible to small changes in functional capacity, but it is useful- and frequently used-for the purpose of classifying patients at entry into clinical trials and describing the global functional consequences of RA (Steinbrocker et al., 1949). Recently, a revised and improved version of the ARA classification of global functional status, that can be used for the same purposes, has been developed and validated (Hochberg et al., 1992); see Table 4 for comparison of the 'old' and 'new' versions.

The most widely used arthritis specific functional ability and health status instruments are the Arthritis Impact Measurement Scales (AIMS) and the Hcalth Assessment Questionnaire (HAQ). Therefore these instruments are described in more detail.

The AIMS1 (formerly called AIMS, until AIMS2 were introduced) have been developed by Meenan and co-workers at Boston University (Meenan et al., 1980, 1984). This self-assessment questionnaire consists of 66 items on physical, psychological and social aspects and medication usage, comorbidity and demographics (Table 5). An item like: Can you prepare a meal? can score one 
Table 3. Properties of functional ability $\&$ health status instruments ${ }^{\mathrm{a}}$.

\begin{tabular}{|c|c|c|c|c|c|}
\hline & \multicolumn{3}{|c|}{ Assessment of Health Dimensions } & \multirow{2}{*}{$\begin{array}{l}\text { Mode of } \\
\text { administration }^{b}\end{array}$} & \multirow{2}{*}{$\begin{array}{l}\text { Time needed } \\
(\mathrm{min})\end{array}$} \\
\hline & Functional & Psychological & Social & & \\
\hline \multicolumn{6}{|c|}{ Generic Measures } \\
\hline IWB & + & - & + & IA & 20 \\
\hline RAND & + & + & + & IA & 60 \\
\hline SIP & + & + & + & SR/IA & 30 \\
\hline \multicolumn{6}{|c|}{ Arthritis Specific Measures } \\
\hline ARA & + & - & - & CJ & short \\
\hline KATZ & + & - & - & IA/OP & 15 \\
\hline KI & + & - & - & OP & 15 \\
\hline LEE & + & - & - & SR & 10 \\
\hline TFCQ & + & - & + & IA & 20 \\
\hline AIMS1 & + & + & + & SR & 20 \\
\hline HAQ & + & - & + & SR & 20 \\
\hline FSI & + & - & + & SR & 30 \\
\hline MHIQ & + & + & + & SR/IA & 20 \\
\hline MACTAR & + & - & + & IA & 20 \\
\hline ARC & + & - & - & CJ & short \\
\hline AIMS2 & + & + & + & SR & 23 \\
\hline
\end{tabular}

${ }^{a}$ See Table 2 for full names and references; the list is not intended to be complete.

'IA, interviewer assessment; SR, self report; CJ, clinical judgment; OP, observed performance.

Table 4. A comparison of the ARA 1949 classification (Steinbrocker) and the ACR 1991 revised criteria of global functional status in rheumatoid arthritis (Steinbrocker et al., 1949; Hochberg et al., 1992)

ARA 1949 Classification

\section{Class I}

Completely able to perform usual activities of daily living: self-care, vocational (work, school, homemaking) and avocational (recreational and leisure)

Class II

Able to perform usual self-care and vocational activities, but limited in avocational activities

\section{Class III}

Able to perform usual self-care activities, but limited in vocational and avocational activities

Class IV

Limited in ability to perform usual self-care, vocational, and avocational activities
Complete functional capacity with ability to carry on all usual duties without handicaps

Functional capacity adequate to conduct normal activities despite handicap of discomfort or limited mobility of one or more joints

Functional capacity adequate to perform only few or none of the duties of usual occupation or of self-care

Largely or wholly incapacitated with patient bedridden or confined to wheelchair, permitting little or no selfcare

${ }^{a}$ In contrary to the 'old' ARA criteria, the 'new' ACR criteria have been validated. 
Table 5. The Arthritis Impact Measurement Scales 1 (AIMS1), long versus short version".

1. Mobility (2: a+d)

a. Travelling around community

b. Using public transportation

c. Having to stay indoors

d. Being bed or chair bound

2. Physical Activity (2: b+d)

a. Vigorous activities

b. Walking blocks, flights of stairs

c. Bending, lifting, stooping

d. Going one block, one flight of stairs

e. Walking assistance

3. Dexterity (2: b+d)

a. Writing with pen

b. Buttoning clothing

c. Turning a key

d. Tying shoes

e. Opening a new jar

4. Household Activity (2: $b+c)$

a. Shopping

b. Preparing meals

c. Doing housework

d. Doing laundry

e. Taking medication

f. Handling money

g. Using telephone

5. Social Activity (2: $a+c)$

a. Getting together with

friends

b. Visits from friends

c. Visiting friends

d. Being on the phone with friends
6. Act. of Daily Life (2:

a+b)

a. Assistance in taking bath, shower

b. Assistance in getting dressed

c. Assistance in using the toilet

d. Being able to move around

7. Pain (2: $a+b)$

a. Grading pain

b. Frequency of severe pain

c. Duration of morning stiffness

d. Frequency of pain in $\geq 2$ joints

8. Depression (2: $b+c)$

a. Enjoying things

b. Being in low spirits

c. Being downhearted

d. Things not turning out well

e. others being better off you being dead

f. Nothing cheering up

9. Anxiety (2: $d+e)$

a. Feeling tense

b. Nervousness

c. Trying to calm down

d. Feeling relaxed

e. Feeling peaceful

f. Being able to relax

10. Health Perceptions (0)

a. Easily getting sick

b. Worrying about health

c. Resistance to illness

d. Catching an illness

11. Arthritis Impact (0)

a. Grading impact of arthritis

\footnotetext{
${ }^{a}$ All items of AIMS1; items of short version are between parentheses. The AIMS1 questionnaire furthermore contains three items concerning health status, used as validation questions and one item about medication usage, three about co-morbidity and nine about demographics. The total number of items is 66 . The scales of the DUTCH-AIMS are analogous to those of AIMSI.
}

to three points ("without any help" one point, "with some difficulty" two points, "unable to do" three points). The first 53 items are converted into 11 scales with a range from 0 to 10 : Mobility, Physical Activity, Dexterity, Household Activity, Social Activity, Activities of Daily Life, Pain, Depression, Anxiety, Health Perceptions (this scale is used for validation purposes only) and Arthritis Impact.

The AIMS1 have been translated in many languages; the Dutch version is called the DUTCH-AIMS (Taal et al., 1989, Jacobs et al., 1992). The scales of the DUTCH-AIMS are analogous to those of AIMS1. Several modified versions of the AIMS1 exist. In the Netherlands also a modificd AIMS is used (Huiskes et al., 1990). The GERI-AIMS have been evaluated for use in geriatric populations (Wallston et al., 1989); in this instrument, to every item of AIMS1 that assesses functional ability, a question has been added, whether the patient attributes the self-reported problem to arthritis or to other causes. A short version of the AIMS1 has been introduced too, that performs well (Hughes et al., 1991). The items of the AIMS1 and the short AIMS are listed in Table 5. Recently, the AIMS1 were revised, expanded and validated; the resulting questionnaire is called AIMS2 (Meenan et al., 1992). New names were given to the revised scales, in order to avoid confusion with the scales in the AIMS1 version. Of all 78 items, the first 57 items are broken down in 12 scales: Mobility level, Walking and bending, Hand and finger function, Arm function, Self-care, Household tasks, Social activities, Support from family and friends, Arthritis pain, Work, Level of tension and Mood (Table 6). Item 58, the scale Satisfaction, ascertains patients' satisfaction with each of these 12 scales. Item 59 asks the respondents to estimate how much of the problem with any of the areas of the 12 scales is attributable to arthritis; this item allows scale scores to be adjusted if problems in a particular area are (also) due to disorders other than arthritis. Item 60 asks the patient to prioritize the three areas in which he or she would most like to see improvement. Items 61-65 assess general perceptions of current and future health; from item 61 the Health Perceptions scale is formed and from item 66 
Table 6. The Arthritis Impact Measurement Scales 2 (AIMS2)".

\section{Mobility Level}

\section{Social Activity}

a. Using car, public transportation

a. Getting together with friends

b. Being out of the house

c. Doing errands

d. Assistance in going outdoors

e. Being bed or chair bound

2. Walking and Bending

a. Vigorous activities

b. Walking blocks, flights of stairs

b. Visits from friends

c. Visiting friends

d. Being on the phone with friends

e. Going to meetings

8. Support from Family

a. Family around for assistance

b. Family sensitive foryour needs

c. Bending, lifting, stooping c. Family interested in your

d. Going one block, one flight of stairs

e. Walking assistance

3. Hand and Finger

Function

a. Writing

b. Buttoning clothing

c. Turning a key

d. Tying a knot or bow

e. Opening a new jar

4. Arm Function

a. Wiping mouth with napkin

b. Putting on pullover

c. Combing, brushing hai

d. Scratching low back

e. reaching above the head c. Working a shorter day

5. Self Care

a. Assistance in taking bath, shower

b. Assistance in getting dressed

c. Assistance in using the toilet problems

d. Family understanding effects of arthritis

\section{Arthritis Pain}

a. Grading pain

b. Frequency of severe pain

c. Frequency of pain in 2 joints

d. Frequency of morning stiffness

e. Sleep disturbance by pain

10. Work

a. Main form of work

b. Frequency of being unable to work

d. Quality of performed work

e. Adaptations in doing the work

11. Level of Tension

a. Feeling tense

b. Nervousness

d. Assistance in going in/ c. Being able to relax out of bed

d. Feeling relaxed

e. Feeling peaceful

12. Mood

a. Shopping

b. Preparing meals

c. Doing housework

d. Doing laundry a. Enjoying things

b. Being in low spirits

c. Things not turning out well

d. Others better off you being dead

e. Nothing cheering up

${ }^{a}$ The first 57 items of AIMS2 that are broken down in 12 scales (Meenan et al., 1992). The AIMS2 furthermore contain the scales Satisfaction, Health Perceptions and Arthritis Impact: see description in the text.

Table 7. The HAQ disability index - the eight categories ${ }^{\mathrm{a}}$ with key words, describing the individual items.

\begin{tabular}{ll}
\hline 1. Dressing and Grooming & 6. Reach \\
- Dressing including & - Get object from \\
shoelaces and buttons & above head \\
- Shampoo hair & - Bend to pick up from \\
2. Arising & floor \\
- Stand up from chair & 7. Grip \\
- Get in of out bed & - Open car doors \\
3. Eating & - Open jars \\
- Cut meat & - Turn faucets on and \\
- Lift cup to mouth & off \\
- Open new milk carton & 8. Activities \\
4. Walking & - Shop \\
- Walk outdoors & - Get in and out car \\
- Climb five steps & - Do chores as \\
5. Hygiene & vacuuming or \\
- Wash \& dry body & yardwork \\
- Take tube bath & \\
- Get on and off toilet & \\
\hline
\end{tabular}

${ }^{a}$ For each of the eight categories, the score is the highest score of the individual items of that scale. Each item scores as follows: 0: 'without any difficulty', 1: 'with some difficulty', 2: 'with much difficulty', 3: 'unable to do'. For each category, the use of aids, devices or help from another person are checked; if needed for an activity, the score of the category is at least 2 . Of all category scores, the mean is taken. So for this index, an overall score from 0 to 3 on a continuous scale is produced.

the scale Arthritis Impact. The other items deal with the type and duration of arthritis, medication usage, comorbidity and demographics. It takes about $23 \mathrm{~min}$ to complete this questionnaire, that like the AIMS1 - can be used in RA and osteoarthritis too.

The HAQ is a self-administered questionnaire that was developed at Stanford University (Fries et al., 1980). It measures four dimensions in 330 items: disability, discomfort, drug side effects and dollar costs. The disability scale, that contains only 24 items and takes about $5 \mathrm{~min}$ to answer, is most widely used (Table 7). Pincus developed a modified version with eight instead of 24 questions on functional ability, adding scales on functional change, patient satisfaction and pain (Pincus et al., 1983). Reliability and va- 
Table 8. Frequency in which each endpoint measure was used in the 32 clinical trials on the effectiveness of long-acting anti-rheumatic drugs in patients with rheumatoid arthritis, published from 1986 through $1990^{\mathrm{a}}$.

\begin{tabular}{|c|c|c|c|c|c|c|}
\hline \multirow[t]{2}{*}{ Endpoint measure } & \multicolumn{2}{|c|}{$\begin{array}{l}\text { Short-term trials }{ }^{\mathrm{b}} \\
(n=11)\end{array}$} & \multicolumn{2}{|c|}{$\begin{array}{l}\text { Long-term trials }{ }^{\mathrm{b}} \\
(n=21)\end{array}$} & \multicolumn{2}{|c|}{$\begin{array}{l}\text { All trials } \\
(n=32)\end{array}$} \\
\hline & $\%$ & $n$ & $\%$ & $n$ & $\%$ & $n$ \\
\hline Morning stiffness & 100 & 11 & 86 & 18 & 91 & 29 \\
\hline Pain & 91 & 10 & 67 & 14 & 75 & 24 \\
\hline Patient's global assessment & 73 & 8 & 71 & 15 & 72 & 23 \\
\hline Physician's global assessment $^{c}$ & 64 & 7 & 43 & 9 & 50 & 16 \\
\hline Joint count ${ }^{\mathrm{d}}$ & 91 & 10 & 95 & 20 & 94 & 30 \\
\hline Joint swelling $^{d}$ & 73 & 8 & 62 & 13 & 66 & 21 \\
\hline PIP circumference & 46 & 5 & 24 & 5 & 31 & 10 \\
\hline Grip strength & 91 & 10 & 90 & 19 & 91 & 29 \\
\hline Walking time ${ }^{c}$ & 55 & 6 & 14 & 3 & 28 & 9 \\
\hline Functional ability & 55 & 6 & 38 & 8 & 44 & 14 \\
\hline Health status & 18 & 2 & 10 & 2 & 13 & 4 \\
\hline Other clinical endpoints & 18 & 2 & 24 & 5 & 22 & 7 \\
\hline ESR & 91 & 10 & 86 & 18 & 88 & 28 \\
\hline CRP & 27 & 3 & 33 & 7 & 31 & 10 \\
\hline Other laboratory endpoints & 73 & 8 & 57 & 12 & 63 & 20 \\
\hline Radiographs $^{\mathrm{c}}$ & 18 & 2 & 48 & 10 & 38 & 12 \\
\hline Cost/effectiveness analysis & 9 & 1 & 0 & $\mathbf{0}$ & 3 & 1 \\
\hline
\end{tabular}

${ }^{a}$ Controlled clinical trials, published in English, searched using a CD-ROM computerized bibliography (Van der Heide et al., 1992).

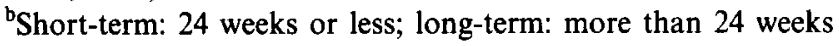

${ }^{c}$ No results reported in 1 trial

${ }^{\mathrm{d}}$ Tender and swollen joint counts: number of inflamed joints, in some cases weighted for severity

lidity of this questionnaire are comparable to that of the original HAQ (American College of Rheumatology, 1988). The so-called transitional questions of this modified $\mathrm{HAQ}$, asking the patient to grade the degree of change in difficulty in accomplishing the specific task compared with three months ago, proved to be more sensitive to change than the conventional HAQ questions (Ziebland et al., 1992). Like the AIMS1, the HAQ has been translated in many languages and several modified versions are available. The British version is similar to the disability index of the HAQ, with only minor changes to the phraseology (Kirwan and Reeback, 1986); other versions have somewhat more changes to the items (Siegert et al., 1984, Van der Heijde et al., 1990, Bijlsma et al., 1990).
How Often - To Date - are Functional Ability and Health Status Instruments Used in Clinical Rheumatological Trials and What is Their Value?

In a review of 32 reports of clinical trials, published in peer reviewed literature from 1986 to 1990, in which the effect of disease modifying anti-rheumatic drugs (DMARDs) was studied, the impact of the applied effect parameters was analyzed (Van der Heide et al., 1992). The frequency in which different outcome variables were used in these trials is given in Table 8. Health status instruments that measure physical as well as psychological and/or social dimensions are used in only $13 \%$ of the reviewed trials. Functional ability separately is measured somewhat more fre- 
Table 9. Frequency in which statistically significant differences between groups were found for each endpoint measure, in trials that report differences in efficacy of the investigated drugs $(n=13)^{\text {a }}$.

\begin{tabular}{lcl}
\hline $\begin{array}{l}\text { Endpoint } \\
\text { measure }\end{array}$ & $\begin{array}{l}\text { Number of } \\
\text { studies, in } \\
\text { which the } \\
\text { the endpoint } \\
\text { was used }\end{array}$ & $\begin{array}{l}\text { frequency of } \\
\text { significant } \\
\text { differences } \\
\text { (\% of } n \text { ) }\end{array}$ \\
& 11 & \\
\hline Morning stiffness & 9 & 27 \\
Pain & 10 & 56 \\
Patient's global & & 30 \\
$\quad$ assessment & 9 & \\
Physician's global & & 44 \\
$\quad$ assessment & 12 & 58 \\
Joint count & 8 & 63 \\
Joint swelling & 6 & 17 \\
PIP circumference & 11 & 36 \\
Grip strength & 6 & 17 \\
Walking time & 6 & 67 \\
Functional ability & 3 & 100 \\
Health status & 10 & 56 \\
ESR & 3 & 67 \\
CRP & 4 & 75 \\
Radiographs & & \\
\hline
\end{tabular}

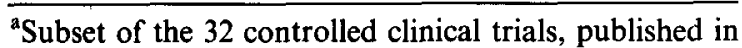
English, on the effectiveness of long-acting antirheumatic drugs in patients with rheumatoid arthritis, published from 1986 through 1990, that were found using a CD-ROM computerized bibliography (Van der Heide et al., 1992). Only the trials that report data on between group statistical analyses of mean or median endpoint values or mean or median changes are included; eight of these 13 trials are placebo controlled

quently: in 14 of the 32 trials functional ability is an outcome measure. In 10 of these 14 trials the investigators used the HAQ disability scale or one of its modified versions.

The relative impact of each of the effect parameters on conclusions about the effectiveness of a DMARD is given in Table 9. The frequency in which statistically significant differences between groups were found for health status measurement, in trials that report differences in efficacy of the investigated anti-rheumatic drugs, is relatively high, although it was used in only three of these 13 trials. The power of functional ability measurements to distinguish between different treatment is relatively high too. The conclusion is therefore, that although functional ability and health status have not been used in clinical RA trials as an evaluation parameter very frequently yet, their sensitivity to detect change seems to be considerable, although the grade of sensitivity might differ between the instruments.

\section{Conclusions and Directions for the Future}

Measuring functional ability and health status in patients with chronic rheumatic diseases can be useful in clinical trials. However, it is not standard yet in this setting. There are many arguments that it should be used more often. In clinical practice, measurement of functional ability and health status is probably useful too in monitoring the followup of patients, assessing the efficacy and side effects of anti-rheumatic drugs.

The use of well known validated instruments is recommended. Two of the most extensively validated and commonly used instruments are the Stanford Health Assessment Questionnaire and the Arthritis Impact Measurement Scales, but in general the other instruments are validated too. The choice of a functional ability or health status instrument should further be determined by the content of the instrument. The instrument that reflects best the areas of interest should be chosen. There is no need to reinvent the wheel and construct one more new instrument. In non English speaking patients, the advantage of the use of a (translated and validated version of an) international well known instrument in comparison with a national questionnaire is that it is generally known and therefore more easy to interpret. Comparison of populations of patients with rheumatic diseases between different countries can thus be facilitated.

In rheumatological health care with many chronic disabled patients the old adage 
'primum est non nocere', meaning that the first principle is not to do harm, should be the keystone of our therapeutic interventions. Health status can be beneficial but also deleteriously influenced by therapeutic interventions, and side-effects can not always clearly be defined by the patients. From this point of view, the assessment of health status in clinical practice and clinical or observational studies, in order to detect ill defined side-effects too, is essential.

\section{References}

American College of Rheumatology. (1988). Dictionary on the rheumatic diseases volume III: health status measurement. New York: Contact Associates International Ltd.

Bell, M.J., Bombardier, C. and Tugwell, P. (1990). Measurement of functional status, quality of life, and utility in rheumatoid arthritis. Arthritis and Rheumatism, 33, 591-601.

Bergner, M., Bobbitt, R.A., Carter, W.B. and Gilson, B.S. (1981). The Sickness Impact Profile: development and final revision of a health status measure. Medical Care, 19, 787-805.

Bijlsma, J.W.J., Oude Heuvel, C.H.B. and Zaalberg, A. (1990). Development and validation of the Dutch questionnaire capacities of daily life (VDF) for patients with rheumatoid arthritis. Journal of Rehabilitation Sciences, 3, 71-74.

Bombardier, C. and Tugwell, P. (1983). Measuring disability: guidelines for rheumatology studies. Journal of Rheumatology, 10 (Suppl 10), 68-73.

Brook, R.H., Ware, J.E. Jr, Davies-Avery, A. et al. (1979). Overview of adult health status measures fielded in Rand's Health Insurance Study. Medical Care 17 (Suppl), 1-131.

Chambers, L.W., McDonald, L.A., Tugwell, P. et al. (1982). The McMaster Health Index Questionnaire as a measure of quality of life in patients with rheumatoid disease. Journal of Rheumatology, 9, 780-784.

Cornelissen, P.G.J., Rasker, J.J. and Valkenburg, H.A. (1988). The arthritis sufferer and the community: a comparison of arthritis sufferers in rural and urban areas. Annals of the Rheumatic Diseases, 47, 150-156.

Fitzpatrick, R., Fletcher, A., Gore, S., Jones, D., Spiegelhalter, D. and Cox, D. (1992). Quality of life measures in health care. I: Applications and issues in assessment. British Medical Journal, 305, 1074-1077.

Fries, J.F., Spitz, P., Kraines, R.G.and Holman, H. (1980). Measurement of patient outcome in arthritis. Arthritis and Rheumatism, 23, 137-145.

Genant, K.H. (1983). Methods of assessing radiographic change in rheumatoid arthritis. American Journal of Medicine, 78, 35-47.

Helewa, A., Goldsmith, C.H. and Smythe, H.A. (1982). Independent measurement of functional capacity in rheumatoid arthritis. Journal of Rheumatology, 9, 794-7.
Hochberg, M.C., Chang, R.W., Dwosh, I., Lindsey, S., Pincus, T. and Wolfe, F. (1992). The American College of Rheumatology 1991 revised criteria for the classification of global functional status in rheumatoid arthritis. Arthritis and Rheumatism, 35, 498-502.

Hughes, S.L., Edelman, P., Chang, R.W., Singer, R.H. and Schuette, P. (1991). The GERI-AIMS. Reliability and validity of the Arthritis Impact Measurement Scales adapted for elderly respondents. Arthritis and Rheumatism, 34, 856-865.

Huiskes, C.J.A.E., Kraaimaat, F.W. and Bijlsma, J.W.J. (1990). Development of a self-report questionnaire to assess the impact of rheumatic diseases on health and lifestyle. Journal of Rehabilitation Sciences, 3, 65-70.

Jacobs, J.W.G., Rasker, J.J., Van Riel, P.L.C.M., Gribnau, F.W.J. and Van de Putte, L.B.A. (1991). Rheumajecta and Vasolastine in the treatment of rheumatoid arthritis. The results of a placebo-controlled, double-blind trial of a complementary treatment. Scandinavian Journal of Rheumatology, 20, 434-440.

Jacobs, J.W.G., Oosterveld, F.G.J., Deuxbouts, N., Rasker, J.J., Taal, E., Dequeker, J. and Uytterhoeven, R. (1992). Rheumatoid arthritis patients' opinion about their own functional capacity: how valid is it? Annals of the Rheumatic Diseases, 51, 765-768.

Jette, A.M. (1980). Functional capacity evaluation: an empirical approach. Archives of Physical and Medical Rehabilitation, 61, 85-9.

Kaplan, R.M., Bush, J.W. and Berry, C.C. (1976). Health status: types of validity for an index of well-being. Health Service Research, 11, 478-507.

Katz, S., Down, T.D. and Cash, H.R. (1970). Progress in development of an index of ADL. Gerontologist, 10, 10-30.

Keitel, W., Hoffmann, H.L., Weber, G. et al. (1971). Ermittlung der prozentualen funktionsminderung der gelenke durch einen bewegungsfunktionstest in der rheumatologie. Deutsches Gesundheitswesen, 26, 1901-1903.

Kirwan, J.R. and Reeback, J.S. (1986). Stanford health assessment questionnaire modified to assess disability in British patients with rheumatoid arthritis. British Journal of Rheumatology, 25, 206-209.

Kirwan, J.R. (1992). A theoretical framework for process, outcome and prognosis in rheumatoid arthritis. Journal of Rheumatology, 19, 333-336.

Lee, P., Jasani, M.K., Dick, W.C. and Buchanan, W.W. (1973). Evaluation of a functional index in rheumatoid arthritis. Scandinavian Journal of Rheumatology, 2, 71-77.

Liang, M.H., Cullen, K.E. and Larson, M.G. (1983). Measuring function and health status in rheumatic disease clinical trials. Clinics in Rheumatic Diseases, 9, 531-539.

Meenan, R.F., Gertman, P.M. and Mason, J.H. (1980). Measuring health status in arthritis: the Arthritis Impact Measurement Scales. Arthritis and Rheumatism, 23, 146-152.

Meenan, R.F., Anderson, J.J., Kazis, L.E. et al. (1984). Outcome assessment in clinical trials: evidence for the sensitivity of a health status measure. Arthritis and Rheumatism, 27, 1344-1352.

Meenan, R.F., Mason, J.H., Anderson, J.J., Guccione, A.A. 
and Kazis, L.E. (1992). AIMS2. The content and properties of a revised and expanded arthritis impact measurement scales health status questionnaire. Arthritis and Rheumatism, $35,1-10$.

Pincus, T., Summey, J.A., Soraci, S.A. Jr et al. (1983). Assessment of patient satisfaction in activities of daily living using a modificd Stanford Health Assessment Questionnaire. Arthritis and Rheumatism, 26, 1346-1353.

Ritchie, D.M., Boyle, J.A., McInnes, J.M., Jasani, M.K., Dalakos, T.G., Grieveson, P. and Buchanan, W.W. (1968). Clinical studies with an articular index for the assessment of joint tenderness in patients with rheumatoid arthritis. Quarterly Journal of Medicine, 37, 393-406.

Siegert, C.E.H., Vleming, L.J., Vandenbroucke, J.P. Cats, A. (1984). Measurement of disability in Dutch rheumatoid arthritis patients. Clinical Rheumatology, 3, 305-309.

Spiegelhalter, D.J., Gore, S.M., Fitzpatrick, R., Fletcher, A.E., Jones, D.R. and Cox, D.R. (1992). Quality of life measures in health care. III: resource allocation. British Medical Journal, 305, 1205-1209.

Steinbrocker, O., Traeger, C.H. and Batterman, R.C. (1949). Therapeutic criteria in rheumatoid arthritis. Journal of the American Medical Association, 140, 659-662.

Taal, E., Jacobs, J.W., Seydel, E.R., Wiegman, O. and Rasker, J.J. (1989). Evaluation of the Dutch Arthritis Impact Measurement Scales (DUTCH-AIMS) in patients with rheumatoid arthritis. British Journal of Rheumatology, 28, 487-491.

Tugwell, P., Bombardier, C., Buchanan, W.W. et al. (1987). The MACTAR patient preference disability questionnaire - an individualized functional priority approach for assess- ing improvement in physical disability in clinical trials in rheumatoid arthritis. Journal of Rheumatology, 14, 446-451.

Van der Heijde, D.M.F.M., Van Riel, P.L.C.M. and Van de Putte, L.B.A. (1990) Sensitivity of a Dutch Health Assessment Questionnaire in a trial comparing hydroxychloroquine vs. sulphasalazine. Scandinavian Journal of Rheumutology, 19, 407-412.

Van der Heide, A., Jacobs, J.W.G., Dinant, H.J. and Bijlsma, J.W.J. (1992). The impact of endpoint measures in rheumatoid arthritis clinical trials. Seminars in Arthritis and Rheumatism, 21, 287-294.

Wallston, K.A., Brown, G.K., Stein, M.J. and Dobbins C.J (1989). Comparing the short and long version of the arthritis impact measurement scales. Journal of Rheumatology, 16, $1105-1109$.

Ziebland, S., Fitzpatrick, R., Jenkinson, C., Mowat, A. and Mowat, A. (1992). Comparison of two approaches to measuring change in health status in rheumatoid arthritis: the Health Assessment Questionnaire (HAQ) and modified HAQ. Annals of the Rheumatic Diseases, 51, 1202-1205.

\section{Correspondence to:}

J.W.G. Jacobs, MD, PhD, Department of Rheumatology F02.223, University Hospital Utrecht, P.O. Box 85500, 3508 GA Utrecht. Netherlands. 